\title{
Pengaruh Variasi Bottom Ash terhadap Sifat Fisik dan Sifat Mekanik pada Mortar Semen
}

\author{
ANNI SUSILOWATI, TSANA OKTAVIANA \\ Jurusan Teknik Sipil, Politeknik Negeri Jakarta, Indonesia \\ Email: anni.susilowati@sipil.pnj.ac.id
}

\begin{abstract}
ABSTRAK
Penggunaan batu bara untuk pembangkit listrik semakin meningkat mengakibatkan menumpuknya limbah bottom ash yang berbahaya untuk lingkungan sekitar. Penelitian ini bertujuan untuk menganalisa pengaruh campuran bottom ash terhadap sifat fisik dan mekanik mortar semen. Metode penelitian yang digunakan adalah metode eksperimental dengan perbandingan campuran yaitu 1PC: 3PS dan variasi bottom ash sebesar 0\%,20\%, 40\%,60\%,80\% terhadap berat pasir. Hasil analisis menunjukkan penggunaan bottom ash menurunkan nilai konsistensi sebesar 1,82\% sampai dengan 45,45\% dibandingkan tanpa penggunaan bottom ash. Penggunaan bottom ash 20\% mampu meningkatkan kuat tekan sebesar 50\% dan kuat lentur sebesar 28,3\% pada umur 28 hari dibandingkan mortar semen tanpa bottom ash. Mortar semen termasuk mortar tipe S sesuai SNI 03-6882-2002.
\end{abstract}

Kata kunci: abu dasar, mortar semen, pengganti agregat halus

\begin{abstract}
The increasing use of coal for power generation results in the accumulation of bottom ash waste which is harmful to the surrounding environment. This study aims to analyze the effect of bottom ash mixture on the physical and mechanical properties of cement mortar. The research method used is an experimental method with a mixture ratio of 1PC: 3PS and bottom ash variations of $0 \%, 20 \%, 40 \%, 60 \%, 80 \%$ by weight of sand. The results of the analysis show that the use of bottom ash reduces the consistency value by $1.82 \%$ to $45.45 \%$ compared to without the use of bottom ash. The use of bottom ash $20 \%$ was able to increase the compressive strength by $50 \%$ and flexural strength by $28.3 \%$ at the age of 28 days compared to cement mortar without bottom ash. Cement mortar including type S mortar according to SNI 03-6882-2002.
\end{abstract}

Keywords: bottom ash, cement mortar, substitute for fine aggregate 


\section{PENDAHULUAN}

Di Indonesia, penggunaan batu bara terbesar berada di sektor pembangkit listrik dan akan terus meningkat. Penggunaan batu bara untuk pembangkit listrik pada tahun 2018 sebesar 56,4\%, terjadi kenaikan sebesar 3\% dibandingkan kapasitas tahun 2017 [10]. PLTU Tanjung Jati B di Jepara menghasilkan fly ash sebanyak 30 ribu ton dan bottom ash sebanyak 5 ribu ton setiap bulannya [6].

Bottom ash merupakan limbah B3 hasil sisa pembakaran batu bara. Limbah B3 adalah zat yang dapat merusak dan membahayakan lingkungan hidup [5]. Bottom ash umumnya memiliki ukuran butir lebih besar dan lebih berat dengan karakteristik berwarna abu-abu gelap. Bottom ash digunakan sebagai bahan substitusi agregat halus dalam pembuatan mortar [7].

Mortar merupakan campuran antara agregat halus (pasir), air dan semen. Mortar sebagai bahan perekat untuk konstruksi struktural digunakan untuk pasangan batu pecah pada pondasi, mortar untuk konstruksi non struktural digunakan pada pasangan bata sebagai bahan pengisi dinding [14].

Abu dasar batubara (bottom ash) memiliki karakteristik butirannya kasar seperti pasir, berwarna hitam ke abu-abuan tidak mengkilat. Bersifat non plastis, tidak berkohesi dan berbutir kasar, serta mempunyai ukuran seperti agregat halus [13]. Bottom ash digunakan untuk bahan alternatif pengganti agregat halus (pasir) pada campuran pembuatan beton, batako, paving, dan lain lain [9].

Hasil penelitian [3], menyebutkan penggunaan bottom ash Ngoro cerah dengan kadar fly ash hingga $50 \%$ dapat meningkatkan kekuatan pada mortar dengan kuat tekan 52,27 $\mathrm{MPa}$ melebihi mortar kontrol dengan kuat tekan 41,60 MPa pada umur 56 hari. Menurut [8] penambahan bottom ash dengan perbandingan 1PC:1BA menghasilkan kuat tekan mortar umur 28 hari tertinggi yaitu 25,868 MPa; dan yang terendah adalah 2,668 MPa.

Menurut [4] kekuatan tekan mortar berbahani dasar semen Portland meningkat ketika penggantian pasir silika dengan bottom ash dibatasi hingga di bawah $40 \%$ dari total agregat halus. Dari hasil penelitian [11] variasi penambahan limbah batubara (bottom ash) dari 10\% sampai 50\% masih dikategorikan masuk pada mutu I. Menurut [12] penambahan campuran bottom ash $100 \%$ sebagai agregat halus meningkatkan ruang pori permeabel mortar masingmasing dari 21,91 menjadi $37,05 \%$ dan 15,48 menjadi $21,31 \%$ dibandingkan dengan campuran kontrol.

Penelitian ini bertujuan untuk mendapatkan sifat fisik dan sifat mekanik mortar yang dihasilkan dengan menggunakan bahan subtitusi sebagian agregat halus dengan bottom ash dan mendapatkan pengaruh bottom ash terhadap sifat fisik dan sifat mekanik mortar. Serta mendapatkan komposisi optimum campuran bottom ash sebagai bahan penganti sebagian agregat halus yang menghasilkan kuat tekan dan kuat lentur mortar paling baik.

\section{METODE PENELITIAN}

Penelitian dilakukan di Laboratorium Uji Bahan Teknik Sipil Politeknik Negeri Jakarta. Bahan yang digunakan pada penelitiani ini adalah sebagai berikut:
a. Agregat halus pasir Bangka.
b. Bottom ash.
c. Semen PCC.
d. Air pada Laboratorium Uji Bahan Teknik Sipil Politeknik Negeri Jakarta. 
Metode penelitian yang dilakukan adalah metode eksperimental dengan membuat benda uji mortar dengan ukuran 50 × 50 × 50 mm untuk uji kuat tekan sesuai dengan SNI 03-68252002, ukuran 25 x 25 x 100 mm untuk uji kuat lentur dan ukuran 25 x 25 x 285 mm untuk uji perubahan panjang. Rancangan campuran mortar semen menggunakan perbandingan volume dengan dikonversikan ke berat masing-masing bahan dan dikoreksi menggunakan berat jenis setiap bahan [1].

Sampel yang telah dibuat selanjutnya diuji pada umur pengujian yang telah ditentukan. Cara perawatan sampel dengan cara merendam sampel ke dalam air agar sampel aman sampai umur pengujian. Selain itu, penelitian ini juga menggunakan metode statistik dengan uji regresi menggunakan software SPSS untuk menganalisis besarnya pengaruh bottom ash terhadap kuat tekan mortar [2].

\section{HASIL DAN PEMBAHASAN}

Berdasarkan hasil pengujian agregat halus diperoleh Tabel $\mathbf{1}$ berikut.

Tabel 1. Hasil Pengujian Agregat

\begin{tabular}{ccccc}
\hline Sifat Bahan & Satuan & $\begin{array}{c}\text { Agregat } \\
\text { Halus }\end{array}$ & $\begin{array}{c}\text { Bottom } \\
\text { Ash }\end{array}$ & Standar \\
\hline Berat Jenis & & 2,56 & 1,77 & $1,6-3,3$ \\
\hline Berat Jenis SSD & & 2,59 & 1,90 & $1,6-3,3$ \\
\hline Berat Isi Padat & $\mathrm{kg} / \mathrm{m}^{3}$ & $1.590,56$ & 995,90 & Rata-rata \\
\hline Berat Isi Lepas & $\mathrm{kg} / \mathrm{m}^{3}$ & $1.465,06$ & 911,16 & $720-1.600$ \\
\hline Penyerapan Air & $\%$ & 1,29 & 7,03 & 3 \\
\hline Kadar Air & $\%$ & 0,16 & 2,00 & \\
\hline Kadar Lumpur & $\%$ & 1,75 & 1 & 5 \\
\hline Modulus Kehalusan Butir & & 2,56 & 2,53 & $2-3$ \\
\hline
\end{tabular}

\subsection{Pengujian Konsistensi}

Pada Gambar 1 didapatkan nilai konsistensi dari setiap variasi bottom ash mengalami penurunan sebesar $1,82 \%$ sampai dengan $45,45 \%$ dibandingkan variasi tanpa bottom ash. Dari hasil nilai konsistensi tersebut nilai konsistensi yang masih memenuhi persyaratan yaitu sebesar $110 \pm 5 \mathrm{~mm}$ ialah mortar semen dengan campuran variasi bottom ash $0 \%$ sampai dengan variasi bottom ash $40 \%$.

Nilai konsistensi pada mortar semen menurun setiap penambahan bottom ash karena penyerapan bottom ash terlalu tinggi, hal ini disebabkan karena bottom ash memiliki permukaan yang kasar dan berongga [3]. Hasil analisis dengan regresi nonlinear quadratic menggunakan software SPSS terlihat pada Gambar 2 dan Gambar 3.

Dari Gambar 2, penggunaan variasi bottom ash berpengaruh kuat terhadapi nilai konsistensi. Hal ini dapat terlihat dari nilai $R$ square sebesar 0,951; yang berarti bahwa variasi bottom ash berpengaruh sebesar $95,1 \%$ terhadap nilai konsistensi. 


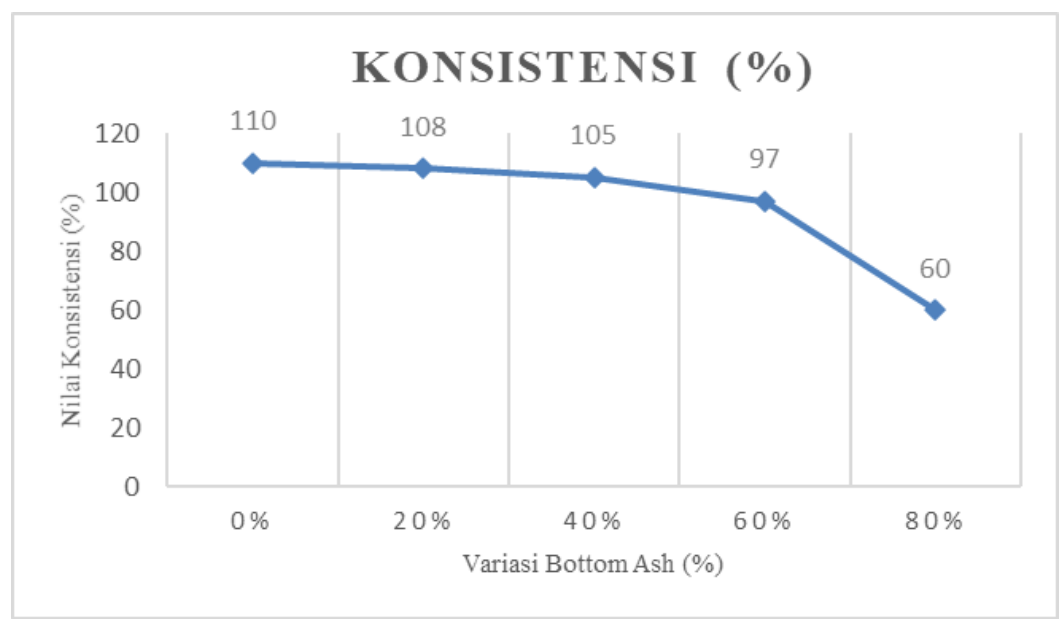

\section{Gambar 1. Nilai konsistensi}

\begin{tabular}{r|r|l|l|}
\multicolumn{9}{c}{ Model Summary } \\
\multirow{2}{*}{ R } & \multicolumn{2}{|c}{$\begin{array}{l}\text { Adjusted R } \\
\text { Square }\end{array}$} & \multicolumn{2}{l}{ Std. Error of the } \\
& R Square & Estimate & \\
\hline .975 & .951 & .902 & 6.485 \\
\hline
\end{tabular}

The independent variable is Variasi Bottom Ash.

Gambar 2. Model summary nilai konsistensi

\begin{tabular}{|c|c|c|c|c|c|}
\hline \multicolumn{6}{|c|}{ ANOVA } \\
\hline & Sum of Squares & df & Mean Square & $\mathrm{F}$ & Sig. \\
\hline Regression & 1633.886 & 2 & 816.943 & 19.425 & .049 \\
\hline Residual & 84.114 & 2 & 42.057 & & \\
\hline Total & 1718.000 & 4 & & & \\
\hline
\end{tabular}

\section{Gambar 3. ANOVA nilai konsistensi}

Berdasarkan Gambar 3, diperoleh nilai signifikansi sebesar 0,049. Nilai signifikansi yang diperoleh 0,049 < 0,05; hal ini menunjukkan bahwa variasi bottom ash berpengaruh secara signifikan terhadap nilai konsistensi.

\subsection{Pengujian Kuat Tekan}

Pada Gambar 4, penggunaan bottom ash 20\% mampu meningkatkan kuat tekan pada berbagai umur pengujian 3, 7, 14, 21 dan 28 hari. Pada umur pengujian 28 hari kuat tekan meningkat sebesar $50 \%$ dibandingkan tanpa penggunaan bottom ash. Penggunaan bottom ash $20 \%$ memiliki kuat tekan tertinggi sebesar $157,55 \mathrm{~kg} / \mathrm{cm}^{2}$ dengan perbandingan campuran bottom ash 1PC:2,4PS:0,6BA dan nilai FAS 0,67; nilainya lebih rendah bila dibandingkan dengan hasil penelitian [8], sebesar 25,85 MPa dengan perbandingan campuran bottom ash 1PC:1BA dan nilai FAS 0,5. Hal ini dikarenakan perbedaan komposisi campuran mortar semen antara penelitian ini dengan penelitian terdahulu. 


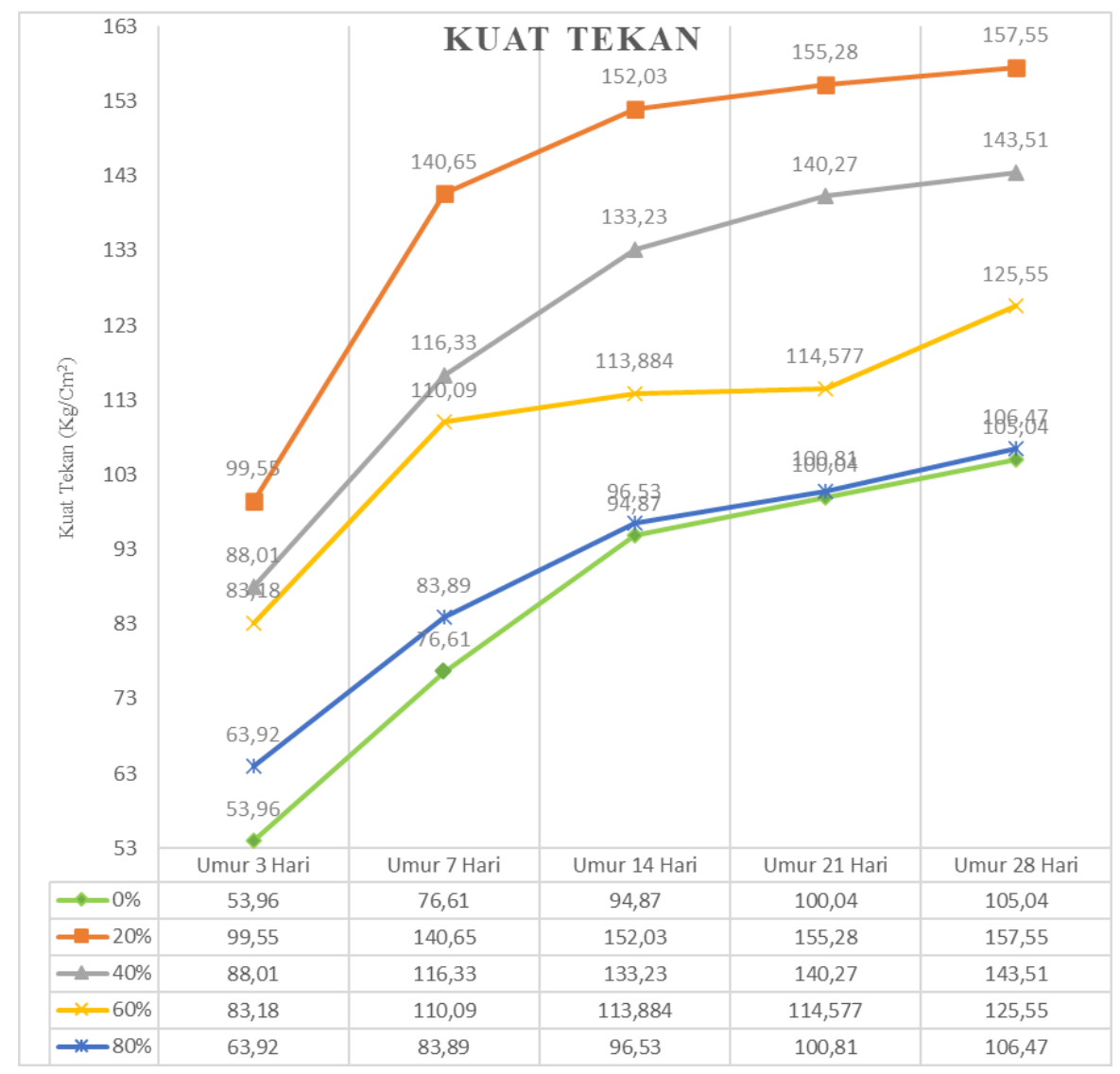

Gambar 4. Nilai kuat tekan

Semakin bertambahnya variasi bottom ash sebanding dengan penurunan hasil kuat tekan. Hal ini dikarenakan bertambahnya ruang pori permeabel, sesuai dengan penelitian [12] penambahan campuran bottom ash $100 \%$ sebagai agregat halus mampu meningkatkan ruang pori permeabel mortar masing-masing dari 21,91 menjadi $37,05 \%$ dan 15,48 menjadi $21,31 \%$ dibandingkan dengan campuran kontrol. Hasil analisis dengan regresi nonlinear cubic menggunakan software SPSS terlihat pada Gambar 5 dan Gambar 6.

\begin{tabular}{|c|c|c|c|}
\hline \multicolumn{4}{|c|}{ Model Summary } \\
\hline $\mathrm{R}$ & R Square & $\begin{array}{l}\text { Adjusted R } \\
\text { Square }\end{array}$ & $\begin{array}{l}\text { Std. Error of the } \\
\text { Estimate }\end{array}$ \\
\hline .988 & .976 & .903 & 7.154 \\
\hline
\end{tabular}

\section{Gambar 5. Model summary nilai kuat tekan umur 28 hari}

Pada Gambar 5 menunjukkan bahwa penggunaan variasi bottom ash berpengaruh kuat terhadap nilai kuat tekan umur 28 hari. Hal ini dapat terlihat dari nilai $R$ square sebesar 0,976 ; yang berarti bahwa variasi bottom ash berpengaruh sebesar $97,6 \%$ terhadap nilai kuat tekan umur 28 hari. 
Anni Susilowati, Tsana Oktaviana

\begin{tabular}{|c|c|c|c|c|c|}
\hline \multicolumn{6}{|c|}{ ANOVA } \\
\hline & Sum of Squares & df & Mean Square & F & Sig. \\
\hline Regression & 2058.741 & 3 & 686.247 & 13.407 & .198 \\
\hline Residual & 51.185 & 1 & 51.185 & & \\
\hline Total & 2109.927 & 4 & & & \\
\hline
\end{tabular}

Gambar 6. ANOVA nilai kuat tekan umur 28 hari

Gambar 6 menunjukkan nilai signifikansi yang diperoleh 0,198 > 0,05; dapat disimpulkan bahwa variasi bottom ash tidak berpengaruh secara signifikan terhadap nilai kuat tekan umur 28 hari.

\subsection{Pengujian Kuat Lentur (28 hari)}

Dari Gambar 7, penggunaan bottom ash sampai $20 \%$ terus mengalami kenaikan nilai kuat lentur, dan menurun pada variasi $40 \%$. Penggunaan bottom ash $20 \%$ mampu meningkatkan kuat lentur 28 hari sebesar $28,3 \%$ dibandingkan tanpa penggunaan bottom ash. Halmana penggunaan bottom ash $20 \%$ memiliki kuat lentur tertinggi sebesar $62,55 \mathrm{~kg} / \mathrm{cm}^{2}$. Untuk penggunaan bottom ash $80 \%$ memiliki nilai kuat lentur paling rendah yaitu sebesar $5,5 \mathrm{~kg} / \mathrm{cm}^{2}$. Hasil analisis dengan regresi nonlinear cubic menggunakan software SPSS terlihat pada Gambar 8 dan Gambar 9.

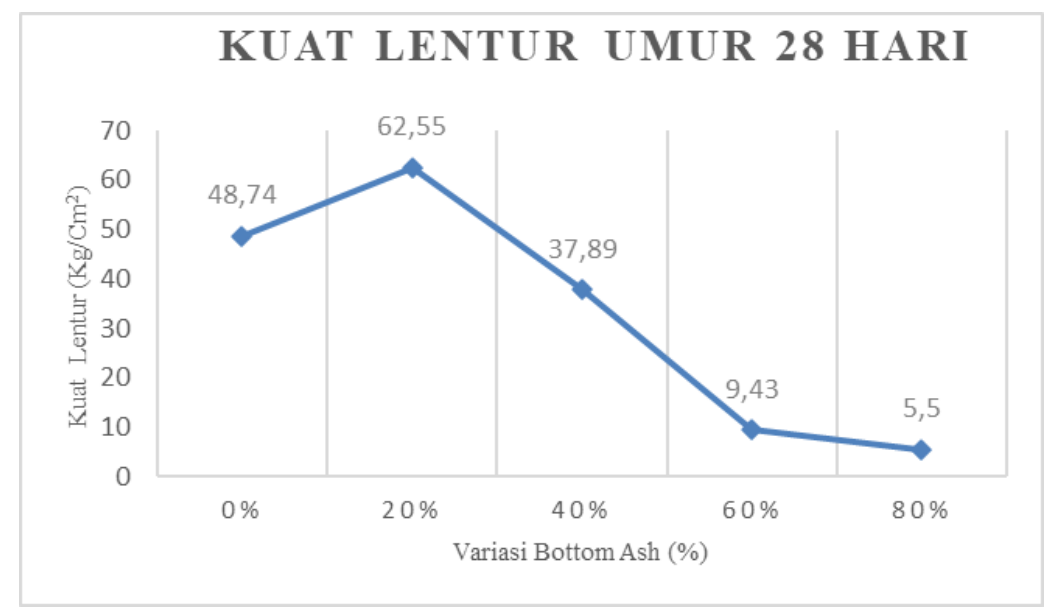

Gambar 7. Nilai kuat lentur umur 28 hari

\begin{tabular}{|c|c|c|c|}
\hline \multicolumn{4}{|c|}{ Model Summary } \\
\hline $\mathrm{R}$ & R Square & $\begin{array}{l}\text { Adjusted R } \\
\text { Square }\end{array}$ & $\begin{array}{l}\text { Std. Error of the } \\
\text { Estimate }\end{array}$ \\
\hline .988 & .976 & .903 & 7.154 \\
\hline
\end{tabular}

\section{Gambar 8. Model summary nilai kuat tekan umur 28 hari}

Pada Gambar 8, penggunaan variasi bottom ash berpengaruh kuat terhadap nilai kuat lentur umur 28 hari. Hal ini dapat terlihat dari nilai $R$ square sebesar 1 , yang berarti bahwa variasi bottom ash berpengaruh sebesar $100 \%$ terhadap nilai kuat lentur umur 28 hari. 


\begin{tabular}{|c|c|c|c|c|c|}
\hline \multicolumn{6}{|c|}{ ANOVA } \\
\hline & Sum of Squares & df & Mean Square & F & Sig. \\
\hline Regression & 4298.824 & 3 & 1432.941 & 5632.504 & .010 \\
\hline Residual & .254 & 1 & .254 & & \\
\hline Total & 4299.078 & 4 & & & \\
\hline
\end{tabular}

Gambar 9. ANOVA nilai kuat lentur umur 28 hari

Berdasarkan Gambar 9, diperoleh nilai signifikansi sebesar 0,010. Nilai signifikansi yang diperoleh 0,010 <0,05; hal ini menunjukkan bahwa variasi bottom ash berpengaruh secara signifikan terhadap nilai kuat lentur umur 28 hari.

\subsection{Pengujian Perubahan Panjang}

Dari Gambar 10, dapat dilihat bahwa secara keseluruhan benda uji dengan variasi bottom ash mengalami muai susut. Pada umur 21 hari variasi bottom ash $60 \%$ mengalami perubahan panjang rata-rata paling kecil yaitu $0,00105 \%$ dan perubahan panjang terbesar pada variasi bottom ash $0 \%$ umur 3 hari $-0,03070 \%$. Hasil analisis dengan regresi nonlinear cubic menggunakan software SPSS terlihat pada Gambar 11 dan Gambar 12.

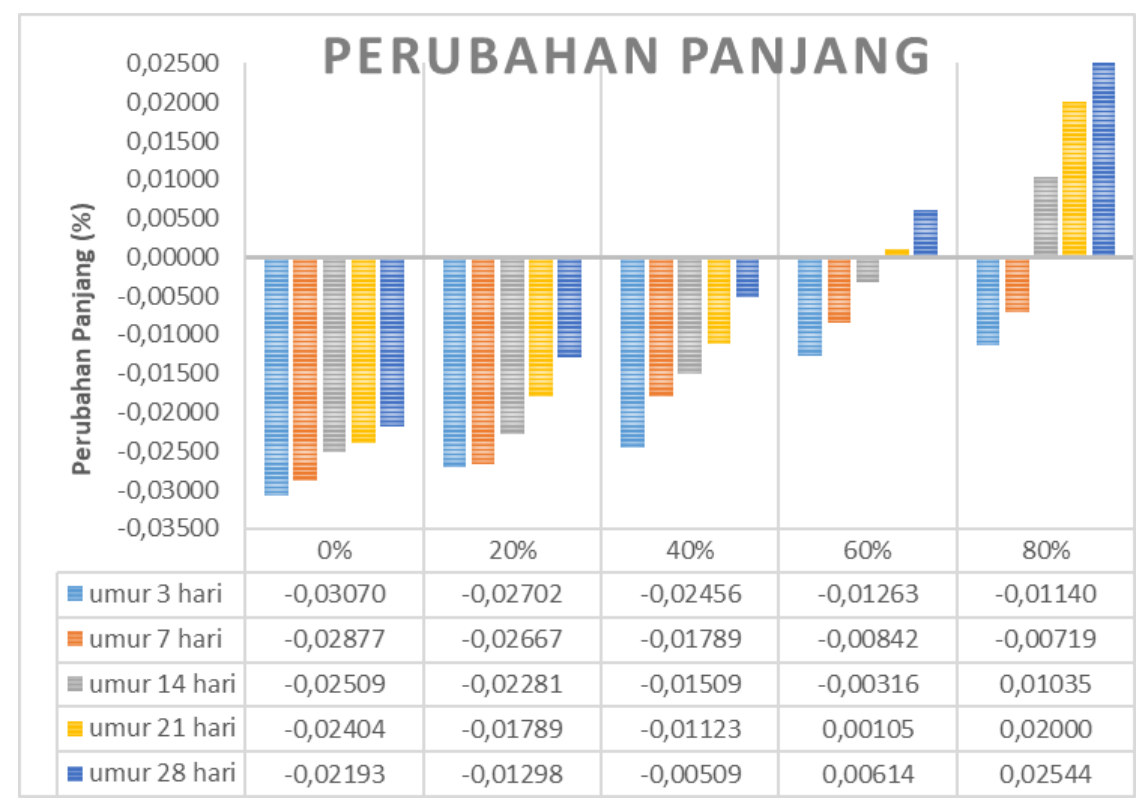

Gambar 10. Nilai perubahan panjang

\begin{tabular}{|c|c|c|c|}
\hline \multicolumn{4}{|c|}{ Model Summary } \\
\hline $\mathrm{R}$ & R Square & $\begin{array}{l}\text { Adjusted R } \\
\text { Square }\end{array}$ & $\begin{array}{l}\text { Std. Error of the } \\
\text { Estimate }\end{array}$ \\
\hline 1.000 & 1.000 & 1.000 & .000 \\
\hline
\end{tabular}

The independent variable is Variasi Bottom Ash

\section{Gambar 11. Model summary nilai perubahan panjang}

Pada Gambar 11, menunjukkan bahwa penggunaan variasi bottom ash berpengaruh kuat terhadap nilai perubahan panjang. Hal ini dapat terlihat dari nilai $R$ square sebesar 1 , yang 
berarti bahwa variasi bottom ash berpengaruh sebesar $100 \%$ terhadap nilai perubahan panjang.

\begin{tabular}{|c|c|c|c|c|c|}
\hline \multicolumn{6}{|c|}{ ANOVA } \\
\hline & Sum of Squares & $\mathrm{df}$ & Mean Square & $\mathrm{F}$ & Sig. \\
\hline Regression & .001 & 3 & .000 & 27545.638 & .004 \\
\hline Residual & .000 & 1 & .000 & & \\
\hline Total & .001 & 4 & & & \\
\hline
\end{tabular}

Gambar 12. ANOVA nilai perubahan panjang

Dari Gambar 12, nilai signifikansi sebesar 0,004. Nilai signifikansi yang diperoleh 0,004< 0,05; hal ini menunjukkan bahwa variasi bottom ash berpengaruh secara signifikan terhadap nilai perubahan panjang.

\section{KESIMPULAN}

Pemanfaatan bottom ash pada agregat halus menurunkan nilai konsistensi berturut-turut sebesar $1,82 \%$ sampai dengan $45,45 \%$ dibandingkan tanpa penggunaan bottomash. Bottom ash dapat dimanfaatkan sebagai pengganti pasir pada pembuatan mortar semen karena penggunaan bottom ash $20 \%$ mampu meningkatkan kuat tekan sebesar $50 \%$ dan kuat lentur sebesar $28,3 \%$ pada umuri 28 hari dibandingkan dengan mortar semen tanpa penggunaan bottom ash. Kadar optimum terdapat pada penggunaan bottom ash $20 \%$ didapat kuat tekan pada umur 28 hari sebesar 157,55 kg/ $\mathrm{cm}^{2}$; termasuk mortar tipe S yaitu mempunyai kekuatan minimum 12,5 MPa (SNI 03-6882-2002). Perubahan panjang secara umum untuk semua variasi benda uji mengalami muai susut.

\section{UCAPAN TERIMA KASIH}

Penulis mengucapkan terima kasih kepada UP2M Politeknik Negeri Jakarta yang telah memberikan bantuan dana sehingga penelitiani ini dapat berjalan dengan lancar.

\section{DAFTAR PUSTAKA}

[1] Anggraini, L., Ramadian, Y., \& Susilowati, A. (2019). Karakteristik Papan Semen Dengan Penggunaan Limbah Botol Polyethylene Terehthalate (PET). In Prosiding Seminar Nasional Teknik Sipil (Vol. 1, No. 1, pp. 113-124).

[2] Bhirawa, W.T. (2020). Proses pengolahan data dari model persamaan regresi dengan menggunakan statistical product and service solution (SPSS). Jurnal Mitra Manajemen, $\pi 1)$.

[3] Chandra, W.H., Yusuf, K.S., Antoni, A., \& Hardjito, D. (2019). Penggunaan Bottom Ash Dari Sistem Pembakaran Circulated Fluidizes Bed Burning Dan Dari BoilerSebagai Agregat Halus Dalam Pembuatan Mortar. Jurnal Dimensi Pratama Teknik Sipil, 8(1), 244-251.

[4] Hashemi, S.S.G., Mahmud, H.B., Djobo, J.N.Y., Tan, C.G., Ang, B.C., \& Ranjbar, N. (2018). Microstructural characterization and mechanical properties of bottom ash mortar. Journal of Cleaner Production, 170, 797-804.

[5] Juliansyah, R.E. (2020). Implementasi Pengawasan Dinas Lingkungan Hidup dalam Pengelolaan Limbah Bahan Berbahaya dan Beracun (B3) di Kawasan Industri Medan Kelurahan Mabar.

[6] Pebrianto, F. ( 2021, April 20). Sisa Limbah Batu Bara yang Belum Bisa Diolah PLN Ada 
di Tempat Ini. TEMPO.CO. Diakses dari https://bisnis.tempo.co/read/1454514/sisalimbah-batu-bara-yang-belum-bisa-diolah-pln-ada-di-tempat-ini/full\&view=ok

[7] Posedung, A.C., Phengkarsa, F., \& Sandy, D. (2020). Pemanfaatan Bottom Ash Sebagai Bahan Substitusi Agregat Halus Terhadap Kekuatan Beton. Paulus Civil Engineering Journal, 2(3), 187-195.

[8] Qomaruddin, M., Saputro, Y.A., \& Sudarno, S. (2018). Kajian Penggunaan Bottom Ash Sebagai Mortar Beton. Prosiding SNST Fakultas Teknik, 1(1).

[9] Qomaruddin, M., \& Sudarno, S. (2017). Pemanfaatan Limbah Bottom Ash Pengganti Agregat Halus Dengan Tambahan Kapur Pada Pembuatan Paving. Reviews in Civil Engineering, 1(1).

[10] Surhayati, Pambudi, S.H., Wibowo, J.L., \& Pratiwi, N.I. (2019). Outlook Energi Indonesia. Diakses dari https://www.esdm.go.id/assets/media/content/content-outlook-energiindonesia-2019-bahasa-indonesia.pdf

[11] Sultan, M.A., Imran, I., \& Sakti, R. (2019). Subtitusi Parsial Agregat Halus Dengan Bottom Ash Pada Pembuatan Bata Semen. Rekayasa Sipil, 13(1), 64-69.

[12] Torkittikul, P., Nochaiya, T., Wongkeo, W., \& Chaipanich, A. (2017). Utilization of coal bottom ash to improve thermal insulation of construction material. Journal of material cycles and waste management, 19(1), 305-317.

[13] Tumingan, T. (2020). Mikrostruktur Dan Kuat Tekan Beton Menggunakan Limbah Abu Batubara (Pond Ash) Sebagai Pengganti Agregat Halus. External Journals Collection.

[14] Zuraidah, S., \& Hastono, B. (2018). Pengaruh Variasi Komposisi Campuran Mortar Terhadap Kuat Tekan. Ge-STRAM: Jurnal Perencanaan dan Rekayasa Sipil, 1(1), 8-13. 